\title{
Exploring Students' Anxiety in Computer-based Oral English Test
}

\author{
Fengyang Shi \\ Non-major English Language Department of Nankai University, Tianjin, China \\ Email: shifengyang2002@126.com
}

\begin{abstract}
The present study examined the state of anxiety in the computer-based oral English test and the impact of the test anxiety on the candidates' performance. 80 subjects were measured with a questionnaire adapted from Sarason's Test Anxiety Scale right after taking an oral English test on computer in a multimedia language lab. Two raters analyzed the correlation between the test anxiety score and that of their oral test. Results showed that there is a relatively high test anxiety in the computer context for a few subjective as well as objective reasons. And also the apprehension of different levels was proved to, more or less, affect the candidates' spoken English performance to some extent. It is suggested that improving testing environment and strengthening pre-test training can be used to reduce the level of anxiety and therefore, help evaluate students' real oral English proficiency.
\end{abstract}

Index Terms - computer-based oral English test, test anxiety, test performance, testing environment

\section{INTRODUCTION}

With the increasing demand of oral English proficiency and the popularity of the computer used in language teaching and testing, more and more universities in China tend to adopt the computer-based oral English test. It is efficient for about 300 students to take the test simultaneously within 30 minutes. Besides, there is interaction between students. However, test-takers' performance is largely affected by various factors, among which test anxiety has long aroused researchers' attention.

\section{A. Test Anxiety}

Anxiety belongs to the cognitive behvaior rising from self-doubt and self-depreciation (Zhang, 2004). It is "a state of apprehension, a vague, sometimes undefined, fear" (Scovel, 1978). Test anxiety has been defined as one element of general anxiety composed of cognitive attentional processes that interferes with competent performance in academic or assessment situations (Spielberger \& Vagg, 1995).

Horwitz pointed out that anxiety is built up to the climax when language learners communicate with others orally and oral test has the potential of provoking both test and oral communication anxiety simultaneously in susceptible students. (Horwits \& Cope, 1986). Therefore, it is reasonable that some test-takers tend to feel extremely apprehensive in the orally evaluative situation. Oral English test anxiety is related to such elements as communicative apprehension (i.e the fear of communicating with others), test anxiety (i.e. general fear of the negative evaluation) and face anxiety (i.e. the fear of the direct threat to one's self-esteem due to the failure in talking with the examiner in oral test). (Han, 2005)

Some researchers have explored the causes of oral test anxiety. Such factors as time limit, test techniques, test format, length, testing environment and clarity of test instructions are believed to cause test anxiety to a certain extent (Young, 1999). Kitano posited that fear of negative evaluaiton and self-perceived speaking ability contribute to the different level of anxiety among test-takers. Sarason held that test anxiety occurs when students who have performed poorly in the past develop negative, irrelevant thoughts during evaluative situation.(Sarason, 1986). Chinese researchers have also obtained some findings on the sources of test anxiety. According to Tian(2006), among seven internal and external factors affecting the level of test anxiety, such items as test self-efficacy, language learning and testing strategies and cognitive interferance are significantly correlated. Xie (2008) suggested that the unfamiliarity or ambiguity of the task may increase the examinees' anxiety.

Besides, researchers have been exploring the relationship between test anxiety and the performance. Sarason (1984) analyzed the nature of test anxiety and its relationship to performance and cognitive interference from the standpoint of attention processes. Sullivan found that high test-anxious individuals would show cognitive impairments on attention and memory skills. Zhang(2004) suggested that the relationship between the CET-SET (National College English Test-Spoken English Test) score and test anxiety is negatively significant. Others hold that task-irrelevant thoughts, such as worries and concerns about self-evaluative aspects of failure contribute greatly to the poor performance.

\section{B. Computer-based Oral English Test}

However, most of the research mentioned above were concerned with the written tests and a few research on oral test anxiety were conducted in the context of traditional face-to-face mode, not to mention the computer-based speaking test. 
In recent years, computer technology began to be used as a substitute for traditional face-to-face oral test. The computer-based oral test is a multimedia English proficiency test delivered by a computer that is intended to elicit and measure knowledge of pronunciation, vocabulary, syntas and cohesion. The computer presents test instructions and test tasks, controlls the preparation and response time, and stores participants' responses. The participants wear headsets and speak into microphones. This highly-efficient testing is adopted by more and more Chinese universities for its time-saving, fatigue-reducing and security. However, does the computer-based oral test increase the degree of anxiety or exert no more effect than the researchers have worried?

Shermis assumed that the acceptance of computerized tests may be hindered by the concern that test performance is linked to computer anxiety. He concluded that examinees feel they may perceive a loss of control over the testing environment, which can increase testing anxiety and reduce performance on subsequent task (Shermis, 1998). He also doubted that computer anxiety in test-taking situations is really an extension of test anxiety.

\section{The Purpose of the Present Study}

The present study aims to explore the degree and causes of anxiety in compter-based oral English test and its effect on students' performance. How much do test-takers feel anxious when taking oral test on computer in the multimedia language lab? What are the causes of such anxiety? How does their anxiety influence their performance in the evaluative situation?

\section{RESEARCH METHOD}

\section{A. Hypotheses}

Two hypotheses have been developed in light of the research target.

1. Some students feel anxious for some reasons when taking oral tests on computer.

2. Students' anxiety influences their speaking performance in the computer-based oral test to some extent.

\section{B. Participants}

The research was conducted in June 2011. 80 freshmen from 2 classes were chosen from a key university which has adopted the computer-based speaking test for 3 years. There are 43 male students and 37 female. The average age is 19.3. They were required to fill in a questionnaire about test anxiety, right after the oral English test of the second semester, which taking up 10 percent of the final examination.

\section{Instrument}

A questionnaire and subsequent interview are both used for investigating computer-base oral test anxiety. After reviewing related literatures, the researchers chose the ones that they thought were the most appropriate for the situation and produced 22 items. The questionnaire is composed of two sections, the first part is concerned with the students' basic information, such as name, age and gender, and the second contains 22 items designed on the basis of Sarason's Test Anxiety Scale (TAS) and researchers' teaching experience. The original TAS is slightly modified by adding 6 statements about the specific context of computer-based oral test. The 22 items concern 4 main variables, namely, computer-based testing environment(6), confidence in language proficiency(6), difficulty and complexity of test(2), and finally, the physical and psychological symptoms of test anxiety(9). Students respond to items based on Likert 5-point scale $(1=$ strongly disagree, $5=$ strongly agree) yielding a range of scores from 22 (lowest test anxiety) to 110 (highest test anxiety). The questionnaire demonstrates high internal consistency, its reliability coefficient is proved to be 0.840 .

TABLE I.

RELIABILITY STATISTICS

\begin{tabular}{|l|l|}
\hline Cronbach's Alpha & N of Items \\
\hline .840 & 22 \\
\hline
\end{tabular}

\section{Achievement Measure}

There are four items in the oral test, including reading aloud and retelling a short passage, picture description and pair discussion. Each student was given 15 minutes to complete all these tasks. Directions of each item were stated clearly on the screen to facilitate students to understand what they were required to do. What's more, a countdown clock was set on the right corner of the screen to remind the students how much time left. The pair for the discussion was randomly chosen by the computer system.

\section{E. Procedure}

Each student was distributed a questionnaire immediately after they had taken the oral test in a multimedia language lab. The aim of the study was explained to them clearly as they were asked to blacken the most suitable choice. Afterwards, 16 students were selected randomly to be interviewed. The interview questions are centered around their true feeling and state of mind while taking the oral test on computer.

Two raters assessed students' performance on the basis of the audio records with the rubric of CET-SET. Each student 
was graded from such aspects as pronunciation, vocabulary, grammar, sentence variety, clarity and coherence of the utterance and so on. The total score is 15 . Both the scores of the test anxiety and students' speaking performance were entered into computer. Then the data was processed by SPSS 18 to detect the degree of computer-based oral test anxiety and the correlation between test anxiety and students' performance.

\section{RESUlts}

A. The State of Test Anxiety

TABLE II.

DESCRIPTIVE STATISTICS OF COMPUTER-BASED TEST ANXIETY SCORE

\begin{tabular}{|l|l|l|l|l|l|}
\hline & $\mathrm{N}$ & Minimum & Maximum & Mean & Std. Deviation \\
\hline Test anxiety in CBST & 80 & 44 & 102 & 74.2500 & 1.5636 \\
\hline \\
PERCENTAGE OF LOW AND HIGH ANXIOUS STUDENTS \\
\hline \begin{tabular}{l} 
TABLE III. \\
\hline Low-anxious \\
\hline High-anxious
\end{tabular}$\quad 6$ Pumber & $7.5 \%$ \\
\hline
\end{tabular}

Table 2 and 3 represent the degree of test anxiety in computer-based oral Engish test.

A score of 55 or below ranks in the low test-anxiety range, any score above 90 signifies high test anxiety, the rest scores in between rank in the medium range.

According to the table, the highest score is 102 , the lowest is 44 , the mean is $74.25 .7 .5 \%$ students scored lower than 55 , however, about $15 \%$, or 12 out of 80 students whose scores were higher than 90 were considered highly-anxious. Undoubtedly, these statistics reflect a relatively high level of anxiety in the computer-based oral test.

TABLE IV.

DESCRIPTIVE INFORMATION FOR COMPUTER-BASED TEST ANXIETY VARIABLES

\begin{tabular}{|l|l|l|l|}
\hline Variables & Mean & Std. Deviation & Std. Error mean \\
\hline Computer-based testing environment & 3.4042 & 1.25797 & .19890 \\
\hline Confidence in language proficiency & 3.4728 & 1.26213 & .19992 \\
\hline Difficulty and complexity & 3.2000 & 1.18105 & .18674 \\
\hline Physical and psychological symptoms & 3.000 & 1.03775 & .16408 \\
\hline
\end{tabular}

Table 4 represents the variables reflecting the level of anxiety in the computer-based speaking evaluation. Except for the physical and psychological symptoms, lack of confidence in one's own language proficiency ranks first, followed by the pressure of computer-based testing environment and difficulty and complexity of the test. To be more specific, as many as 70 percent of students admitted that in computer context, the short preparation time (5) and limited answering time (6) contributed to their anxiety, the means of these two items are 4.0750 and 3.650 respectively. However, not many students worry about the operation of computer (mean=2.8000), they did not think it would increase the level of anxiety. Almost 60 percent of students felt unnatural and strange talking to computer, the mean is 3.5750, at the same time, 47.5 percent of students reported that the unfamilarity of the discussion partner chosen by the computer system also made them worry whether they could cooperate well and communicate smoothly. The high mean of lack of confidence in language proficiency reflects the main concern of the oral test of any form, and it is more salient in the computer situation.

In the subsequent interview, one student said "I feel extremely anxious when the time shown on the screen is running quickly. I'm afraid that I'll not complete all the task before the time runs out. So I can't concentrate on the topic, instead, I'm in constant dread... I can't fully express what I want to say. It has definitely affects my performance." Another student reported "I feel strange to talk to a machine which seems cold, emotionless and above all, ridiculous. Although I have the experience of chatting via computer, I still feel anxious in such an evaluative situation."...

\section{B. The Impact of Students'Anxiety on Speaking Performance}

TABLE V.

DESCRIPTIVE STATISTICS

\begin{tabular}{|l|l|l|l|}
\hline & Mean & Std. Deviation & N \\
\hline a15 & 74.2500 & 15.63650 & 80 \\
$\mathrm{~S}$ & 10.6625 & 1.72607 & 80 \\
\hline
\end{tabular}


TABLE VI

CORRELATIONS BETWEEN TEST ANXIETY SCORE AND SPEAKING TEST SCORE

\begin{tabular}{|ll|l|l|}
\hline \multicolumn{2}{|c|}{} & Test Anxiety Score & Speaking Test Score \\
\hline Test Anxiety Score & Pearson Correlation & 1 & $-.669^{* *}$ \\
& Sig. (2-tailed) & & .000 \\
& $\mathrm{~N}$ & 80 & 80 \\
\hline Speaking Test Score & Pearson Correlation & $-.669^{* *}$ & 1 \\
& Sig. (2-tailed) & .000 & \\
$\mathrm{~N}$ & 80 & 80 \\
\hline
\end{tabular}

TABLE VII

AVERAGE MEAN OF TEST ANXIETY AND ORAL TEST SCORE OF HIGH- AND LOW-ANXIOUS STUDENTS

\begin{tabular}{|l|l|l|l|}
\hline & $\mathrm{N}$ & Test Anxiety Score Mean & Oral Test Mean \\
\hline High-anxious (above 90) & 18 & 95.78 & 9 \\
\hline Low-anxious (below 55) & 6 & 49.33 & 12.5 \\
\hline
\end{tabular}

From Table 6, we can see the correlation coefficient of the test anxiety score and speaking test score is -0.669 , which indicates the correlation between them is negatively significant at the level of 0.01 . In other words, the more anxious the students feel, the more poorly they perform in the computer-based speaking test. The negative correlation is also reflected from Table 7, in which high-anxious students score 95.78 in test anxiety on average, but the average score of speaking test is as low as 9, much lower than that of the low-anxious students. The above statistics reveal that the anxiety in the evaluative situation affects how students perform in oral test. Judging from the audio records of their speech, high-anxious students tend to make more errors in pronounciation, grammar and word collocation etc.

\section{DISCUSSION}

The present study indicates that the level of anxiety is relatively high among students taking oral test in the computer context. And meanwhile, the anxiety influences students' performance in computer-based oral English test. A few subjective and objective factors can account for the issue.

\section{A. Factors Causing Test Anxiety in Computer-based Oral English Test}

1. Subjective reasons

According to the present study, there are several factors contributing to the anxiety while the candidates are taking oral test via computer.

First, they are inexperienced in taking computer-based test, especially speaking test. Although the modern college students are labelled as the Internet Generation, they still lack the real experience of communicating orally via computer, not to mention in the evaluative situation. The strange / ridicular feeling and unnaturalness of talking with computer increase their apprehension.

Second, poor ability of time management on computer also influences how they perform. Some students worried that they cannot complete all the tasks within the given time, so they talked very quickly, with errors in grammar and vocabulary being ignorant. They stared at the time-running bar, the fast movement of the time even accelerated their breathing rate and heart beat, it may distract their attention, and made them think something irrelevant, such as what if I cannot finish within the limited time. These irrelevant thoughts, in turn, must affect their normal attention which should be paid to the test itself, therefore, definitely affected the accuracy of their speech. But when finishing all the required tasks, they found time had not run out, so they had to keep silent or add some inconsistent information. Therefore, their failure to manage time reflects their lack of metacognitive strategy, which is regarded as a critical determinant for success in language learning and testing.

Thirdly, poor self-efficacy influences students' confidence in handling the oral test. Those who always thought they would not do well in any evaluation would be more anxious. And what's more, the unpleasant past experience, such as, bad score also had a negative psychological impact on the ongoing test. One interviewee said "I'm afraid of being given low mark for my poor performance partly because of the unsatisfied performance and very low score I got last semester."

2. Objective reasons

In addition to the subjective factors mentioned above, there are also a few objective reasons, especially the uncontrollable testing environment.

Firstly, those who perceived a lack of control over the noise in the multimedia language lab showed increased feelings of helplessness and reduced performance on subsequent task. When they took oral exam on computer, peer's loud voice may influence the normal performance of the examinee. The thought that they've lost the control over the testing environment, more or less, increased their anxiety.

Secondly, the lack of cooperation with the discussion partner also leads to anxiety to some extent. The partner of pair 
is selected randomly, so two speakers are not familiar with each other. Above all, they couldn't rely on the body language (the facial expression, the gestures etc.) to express and interpret the feelings. Besides, mostly the two speakers sit far away from each other though in the same room. Therefore, lack of full understanding and smooth communication will increase the degree of apprehension.

Thirdly, degree of difficulty and complexity of test also turn out to be a factor affecting the examinees' emotionality. One student complained in the interview that once spotting the topic which was beyond his expectation or which he was not so familiar with, his mind would go blank and couldn't speak anything. It is suggested that topics should be interesting, up-to-date, specific, useful, controversial and closely related to students' life. In this case, anxiety disturbs the recall of prior learning and thus degrades performance. It is consistent with Young's findings "In language testing, the greater the degree of evaluation and the more unfamiliar and ambiguous the test tasks and formats, the higher the learners' anxiety is produced.

\section{B. Negative Impacts of Test Anxiety on Students'Speaking Performance}

According to the findings, there are a few negative impacts of test anxiety on students' speaking performance, mainly in the impairment of language proficiency.

First, the participants' language proficiency reflected in the speaking test has been partly impaired by their anxiety. Judging from the audio records, those whose test anxiety scores are high made more errors in pronunciation, grammar and sentence arrangement. In retelling section, some high-anxious students suffered from distorted pronunciation, inaccurate verb tense, incorrect word collocation, even misunderstanding of the passage. One student admitted later "my voice trembled badly for the extreme anxiety, and I even failed to pronounce some words correctly. If it is not in the speaking test, I guess I would not make such silly mistakes." The frequent procrastination is another reflection of the anxiety. Besides, in the picture description section, the high-anxious students failed to identify the most striking information which should not be ignored. Undoubtedly, the students' real language proficiency is not fully reflected because of their anxiety.

Secondly, high degree of anxiety also affects students' working memory, which has been reflected in their performance of retelling. Judging from the records, some high-anxious students forgot retelling important information for the reasons that their attention was partly distracted by irrelevant thoughts. Such thoughts which were not related to the task must have occupied the place in the brain where the useful information should take up. As a result, the impairment of the normal working memory definitely affects the performance.

Thirdly, constant anxiety in speaking test may mar the candidates' self-efficacy and self-confidence. On the one hand, the fear of negative evaluation triggers anxiety in the test, which affects the performance; on the other hand, the poor performance, in turn, impairs the confidence and self-efficacy, which will increase the degree of anxiety. The malignant cycle will impose great pressure on the students psychologically and influence their performance in the future speaking tests.

\section{IMPLICATION}

This research is somewhat significant in China where an increasing number of universities have adopted the computer-based oral English test for improving the efficiency of speaking test. There are a few implications for the test takers, teachers and researchers respectively.

\section{A. Improving the Testing Environment of the Computer-based Oral English Test}

Firstly, in the computer-context the pair system in discussion section can be innovated by selecting two students sitting next to each other or utilizing the technology of video talking. In this case, the two speakers can communicate face-to-face, which may reduce certain load of apprehension caused by the unfamiliarity of the partner and enable them to identify the other party's body language as well.

\section{B. Strengthening Pre-test Training}

Megacognitive strategy such as the management of time should be well trained in classroom teaching. What's more, the school administration should provide students with more opportunities to practice speaking at normal time in multimedia language lab by imitating the testing environment. As a result, students will familiarize the new form of communication and build up confidence and reduce their anxiety as well.

\section{CONCLUSION}

The present study has explored the state of anxiety in the computer-based speaking test and concluded that students indeed feel anxious when taking speaking test on computer and the anxiety, more or less, affects their performance in the test. The findings would enable the researchers to further improve the testing environment of computer-administered test and create more feasible means to help reduce students' anxiety so that their real language proficiency could be examined.

The small number of the samples restricts the results of the study, therefore further research in a larger quantity of subjects is needed. In addition, the negative impacts of test anxiety on the speaking performance could be investigated 
in more specific aspects, such as at the level of pronunciation, grammar, vocabulary and discourse etc in the future research.

\section{REFERENCES}

[1] Amiryousefi, M. \& Tavakoli, M. (2011). The relationship between test anxiety, motivation and MI and the TOEFL iBT Reading, Listening and Writing Scores. Procedia Social and Behavioral Sciences, 15, 210-214.

[2] Cassady, C. J. \& Johnson, E.R. (2002). Cognitive test anxiety and academic performance. Contemporary Educational Psychology, 27, 270-295.

[3] Choi, I. \& Kim, K. S. (2003). Comparability of a paper-based language test and a computer-based language test. Language Testing, 20, 295-320.

[4] DordiNejada, F. G. \& Hakimi, H. (2011). On the relationship between test anxiety and academic performance. Procedia Social and Behavioral Sciences, 15, 3774-3778.

[5] Han, W. F. \&Li, Y. L. (2005) Anxiety in oral English proficiency test. Research in Foreign Language and Literature, 5(1), $55-62$.

[6] Horwitz, E. K., Horwitz, M. B., \& Cope, J. (1986). Foreign language classroom anxiety. The Modern Language Journal, 70(2), $125-132$.

[7] Onyeizugbo, E. U. (2010). Self-efficacy and test anxiety as correlates of academic performance. Educational Research, 1(10), 477-480.

[8] Sarason, I. G. (1984). Stress, anxiety, and cognitive interference: reactions to tests. Journal of Personality and Social Psychology, 46, 929-938.

[9] Sapsirin, S. \& Prapphal, K. (2009). Strategies used in taking a computer-based speaking test: a retrospective verbal protocol study. Journal of Humanities Regular, 12.1, 73-96.

[10] Scovel, T. (1978). The effect of affect on foreign language learning: A review of the anxiety research. Language Learning, 28, 129-142.

[11] Shen L. \& Wang X. H. (2010). A study on the anxiety by the test-takers of a computer-mediated oral English test. Foreign Language Learning: Theory and Practice, 2, 51-58.

[12] Shermis, M.D. \& Lombard, D. (1998). Effects of Computer-Based Test Administrations on Test Anxiety and Performance. Computers in Human Behavior, 14, 111- 123.

[13] Spielberger, C. D. \& Vagg P. R. (1995). Test anxiety: A transactional process model. In Spielberger C. D. \& Vagg P.R.( eds. ). Test Anxiety: Theory, Assessment and Treatment. W ashington, D. C. : Taylor \& Francis.

[14] Tian, B. \& Guo, D.J. (2004). The basic model of test anxiety influencing test performance. Psychological Science, 27(6), 1360-1364.

[15] Tryon, G. S. (1980). The measurement and treatment of test anxiety. Review of Educational Research, 50(2), 343-372.

[16] Yang, Y. X. \& Li, M.T. (2010). A study on computer attitudes of college students in the computer-based oral English test environment. Foreign Language World, 6, 78-84.

[17] Young, D. J. (1991). Creating a low-anxiety classroom environment: What does language anxiety research suggest? Modern Language Journal, 75(4), 427-439.

[18] Zhang, Y. X. (2004). A Study of the candidates' test anxiety in the CET-SET context. MA Dissertation, Chongqing University.

Fengyang Shi was born in 1971. She received her M.A. degree in English Literature from Nankai University, China in 2000.

She has been teaching college English since 1994 and is a lecturer in Non-Major English Language Department of College of Foreign Language, Nankai University. Her research interests consist of TEFL, teacher professional development and testing. She has published a few academic papers including "Study of vocabulary teaching based on the $v .+n$. collocational errors in CLEC" in Journal of Tianjin Foreign Studies University (2007) and "Study of the language input in college oral English teaching from the lexical-chunks perspective" in Journal of Tianjin University of Technology and Education (2007). 